\title{
Promoting IEEE - Women in Engineering Experiences in Ecuador
}

\author{
Victoria Yánez Garzón ${ }^{1}$, Andrea López López ${ }^{2}$ \\ ${ }^{1}$ Universidad de las Fuerzas Armadas ESPE, Ecuador, victoria.yanez@ieee.org \\ ${ }^{2}$ Universidad de las Fuerzas Armadas ESPE, Ecuador, amlopez13@espe.edu.ec
}

\begin{abstract}
The problem involving women in developing and participating in STEM areas (science, technology, engineering, and mathematics) motivates several organizations worldwide to look for strategies and methodologies that encourage women and girls to approach science. In Latin America, especially in Ecuador, women who are pursuing their undergraduate university studies related to these fields represent a considerable number. This document intends to present the achievements of the activities organized by the WIE (Women In Engineering) affinity group of the Student Branch of the Universidad de las Fuerzas Armadas through strategies, organization, and development of various events that focus on involving more members and professionals to take part in several projects that promote the integration of women and girls in science. The initiatives carried out by this team, formed by men and women, encourage the new generations of the country to contemplate engineering careers in their future enthusiastically.
\end{abstract}

Index Terms-Women in Engineering, IEEE, WIE, STEM.

\section{INTRODUCTION}

The WIE or Women in Engineering affinity group of IEEE (Institute of Electrical and Electronics Engineers) is a worldwide initiative. It is a group of volunteer members whose objective is to promote and involve more women in the field of science and engineering, thus inspiring girls from different levels of education to pursue their academic interests to train in an engineering career. [1]

Projects like this work for the empowerment of women in science with an emphasis on their presence in engineering.

Worldwide the gender gap has existed for several years in areas of science, technology, and mathematics or commonly called by its acronym, STEM. In recent years, higher education has evidenced the growth in numbers for women in engineering careers; however, it is still shown as an underrepresented group. According to the United Nations Educational, Scientific and Cultural Organization, UNESCO, only 35\% of students enrolled in STEM careers are women. Until 2016 the percentage of women involved in higher education, globally, in information technology was $28 \%$ and in engineering, manufacturing, and construction 27\%; Very notable differences in these disciplines that make consequent the fact that only $28 \%$ of the total of researchers around the world are women.[2]

In this context, it is found in Ecuador, that $55 \%$ of the total students of higher education are women. A more in-depth analysis conducted by [3] shows that in careers related to areas of science and technology, the female figure only represents $23 \%$ in engineering, industry, and construction; and 38\% in life sciences, mathematics, computer science. Additionally, the data obtained from work entitled "Women and Men of Ecuador in Numbers III - strategic information series," of the Engineering in Physical and Mathematical Sciences only $29 \%$ corresponds to women. Among the causes of these figures are gender stereotypes, family environment, and support, school environment, lack of reference models, and economic resources for access to technical higher education. [4]

Official organizations have already added to their agenda new initiatives of women in STEM in Ecuador, and others have carried out action-based movements. It is possible to find public and private organizations such as Girls in Tech Ecuador, Coalición STEM (STEM Coalition), Red Ecuatoriana de Mujeres Científicas REMCI (Ecuadorian Network of Scientific Women) and the Ministry of Education of Ecuador. This last one in joint work with UNESCO, incorporating a digital educational agenda with a day that included the following workshops: Evening "Girls and Women in the Science: sowing referents," "Use of tangible materials for the teaching of Mathematics" and "The world of Eugenie. I have fun with science!" carried out during the year 2019.

This article presents the set of activities and strategies established by Women in Engineering Affinity Group of IEEE to work on effective solutions to the issues presented as a long-term project. Which were implemented with girls and boys between 11 and 15 years old from different schools in the city of Quito and Sangolquí; and with the young students of the technical careers of the Universidad de las Fuerzas Armadas ESPE such as Mechatronics Engineering, Electronic Engineering in Automation and Control, Electronic and Telecommunications Engineering, Systems and Software Engineering and Biotechnology Engineering.

The different sections of the exposed article show the importance and trajectory of WIE ESPE in the community, not only in the university community but local, too, since its creation, the aspects that have allowed it to be consolidated, and those that allow it to meet its objectives.

\section{INSTITUTIONAL ORGANIZATION}

Women in Engineering is part of the IEEE Student Branch of the Universidad de las Fuerzas Armadas ESPE. It is a team made up of students from various university engineering programs and levels - volunteers with a professional and personal commitment to the advancement of technology for humanity. 
The mission and vision of IEEE WiE ESPE align with global WIE guidelines. Its mission is to inspire and involve girls and young women from communities and institutions in technical disciplines by having a clear vision of teamwork of peers who support the integral formation of children and youth.[5]

Based on these aspects, WiE ESPE carries out activities that include academia and projects link to society.

The group was activated in 2018 by the president of the IEEE ESPE Student Branch of that year, the Elected Coordinator of the Affinity Group, and the Student Branch Advisor, who is an IEEE professional member and teacher of the university. As a student organizational unit belonging to IEEE, its operation is mostly governed by the MORE, IEEE Student Branch Operations Manual (Manual de Operaciones para Ramas Estudiantiles IEEE) of Region 9 (Latin America and the Caribbean) and the IEEE Code of Ethics.[6] .

The activities are carried out through the approval of the assembly (members and directors of Wie and the Student Branch) and the Group Executive Committee formed by the acting coordinator, group advisor, and the Student Branch president. The process is defined in the following steps:

1) WIE members and volunteers propose the ideas of activities, events, or projects..

2) Proposal preparation by the management members or event leaders.

3) Proposal approval by the executive committee.

4) Activity planning (objectives, schedule, scope, place).

5) Execution phase by student members.
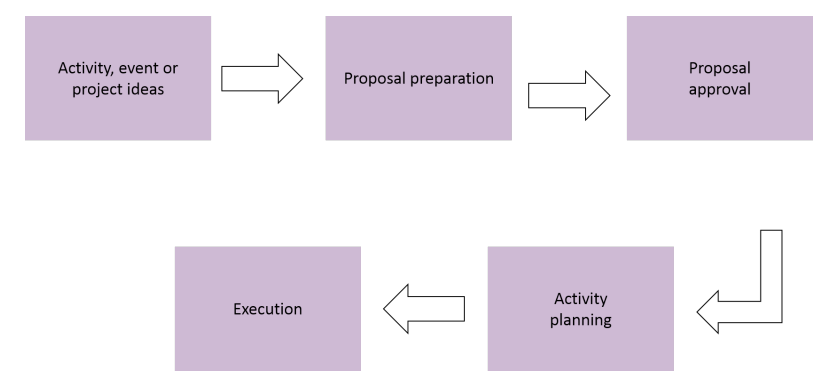

Fig. 1. Process of approval and execution of WIE activities

The members of the group are organized in different tasks, programming, logistics, and advertising. Programming tasks such as organization and supervision of the event are executed according to the schedule. The volunteers in charge to help in the logistics part make sure to request spaces and permits on the campus depending on the event, and those in charge of advertising are volunteers with software design skills to sketch flyers and promotional posters that are posted on social media or printed. This distribution of tasks allows giving each member a job to sow in them a feeling of importance, ensures the learning of soft skills and motivation to belong to a team outside their curricular activities.

All this allows having a solid group of men and women who work to include more girls in technical careers and motivate those in them not to give up.

\section{Strategies And Project Execution}

The realization of events and projects address prior planning that includes objectives, a work schedule, and the scope or audience that it is needed to be reached.

\section{A. Strategies}

After reviewing the main factors that affect the minority participation of women in science and technology, contained in social levels, early education, family and early learning cite UNESCO1, WIE members of the campus established different strategies in order of being able to cover factors in which action operations can be exercised within the capabilities of the student group. These are the general tactics that work with the members and student managers supported by the ESPE departments and faculties:

1) Visibility of successful women in history, "role models" through the creation of social media content.

2) Motivational programs and activities for young women in technical careers of the University.

3) Taking advantage of important dates and international commemorations to execute attractive events and commemorate them with the academic community.

4) Educational robotics workshops for boys and girls of primary education of schools and colleges located in the province.

For the first point, the derived strategies are concentrated in the social networks with the most significant impact on youth, Facebook, and Instagram, with a reach of 1915 and 507 followers, respectively, until February 2020. Through these campaigns, the visibility of women engineers and scientists in history is carried out, which helps us to maintain the interest of girls in their studies. According to a study by Microsoft, approximately 11500 European girls identify with female role models or inspirational models to follow. For this reason, through flyer design and its publication, biographies of important women not known in history such as Ada Lovelace, Rosalind Franklin, Grace Hopper, and others are presented to the community of social media network.

The academic events and competitions organized by the different university careers are used, especially those organized by clubs and other student technical chapters of the IEEE ESPE Branch, such as the ILA Robotics Contest - RAS v4.0, organized by the Chapter IEEE RAS (Robotics Automation Society) of the Student Branch in May 2019. The intention of using this type of event is to recognize the effort of the finalist teams of the different categories formed by women since the participation of the girls. It is also significantly reduced due to the low number of female students in the electronics and mechatronics careers that participate in these types of challenges. In this way, we encourage more girls to participate in these activities.

The International Day of Girl and the Woman in Science, the International Day of Girls in the TICs, and the Day of the Female Engineer are some of the critical dates that WIE ESPE uses to organize events with greater magnitude 


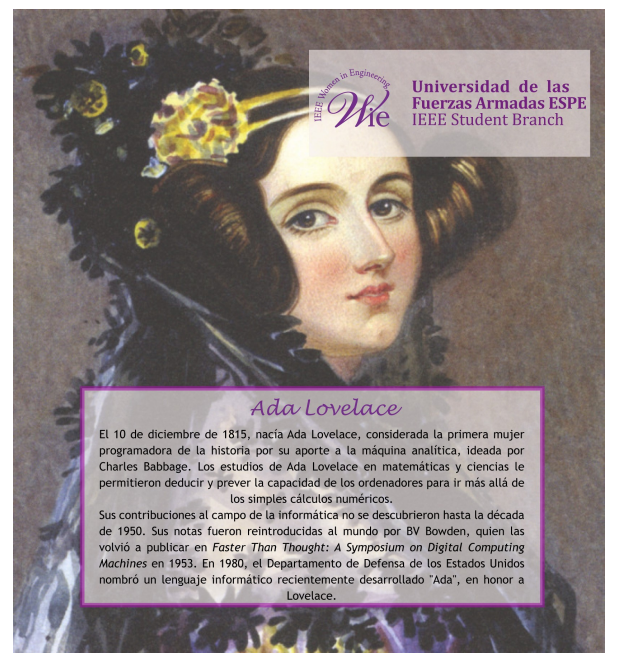

Fig. 2. "Role models"content for social media published on October 8th of 2019

inside and outside the university. WIE members participate in the same way, in commemorative events of WIE groups of several universities, representing the university organization, this with local support, such as transportation management for the attendance of students to these events.

The intervention that has been carried out has been at the individual, school, and society level. Individual work is observed as it is planned to work directly with children, based on a guiding document, IEEE Activities with Children [7], to focus and shape the skills of girls towards STEM studies. At the school level, it was devised that teachers take part in the workshops given to children to replicate the work done by Wie ESPE volunteers in the classrooms. Furthermore, regarding society, we have sought to chat with young people to eliminate or clarify thoughts about gender stereotypes and cultural beliefs that place them in the future with professions in the fields of social and non-technical sciences. Young people should know that they can be suitable for any profession and if they have not been part of it in some way, show them in an ingenious, fun and educational way the wonderful world of engineering, mathematics, and science.

\section{B. Project Execution}

It should be noted that all these activities went through a planning process that follows the affinity group. Besides, aspects such as their dissemination have been taken into consideration, to establish collaborative ties with companies and organizations positioned in this field of empowerment of technologies and engineering.

1) Discussion "Role of Women in Engineering" and Technical Talks: The event was carried out in January 2019, where professional women from academia and industry were summoned to relate their experiences and livings throughout their trajectories. Among the guests was the Engineer Andrea Carrión, current Coordinator of Wie Group of IEEE Ecuador
Section. The discussion also was attended by a professional who performs her duties in Movistar and the academy, the Captain of the Armed Forces who studied at the ESPE.

2) Workshops for Girls' Day in ICTs: Launched in June 2019 , the most considerable activity in scope that the affinity group has organized. The Department of Energy and Mechanical Sciences of the University, the National Directorate of Education of Technologies for Education, DNTE and the company CR Science and Robotics were the sponsors and collaborators taught robotics workshops to a total of 40 students, girls and Children between 11 and 14 years old by WiW ESPE members. The "Digital Education" project was launched, part of the agreement that combines efforts between the Ministry of Education and the University of the Armed Forces ESPE. The entire execution was developed by young women and men WiE students. The workshop consisted of the following phases and activities with the children and teachers of the Educational Unit:

a. Welcome by the authorities of the University, Student Branch and Affinity Group.

b. Video presentation and talk to children and teachers about gender stereotypes by Coordinator Wie ESPE 2019, student of Mechatronics Engineering.

c. A dynamic was carried out by member Chair of the IEEE ESPE 2018 Branch, student of Electronics, Automation, and Control Engineering, with the theme "How it works and how I build my robot." To energize the children and make them part of the presentation. This mechanic allows children to be shown through everyday movements and tasks in a child acting like a robot, the model of its operation through instructions and orders.

d. Five different stations were placed and the children were divided into mixed groups of 10 people. For each station, children received a different workshop, tasks and exhibitions.

- The first work station presented educational electronic devices, Neulog Logger Sensors, which allow them to be connected in a chain, acquire data, and analyze them on a computer through software. Ideal for teaching children how to capture the magnitudes and variables of the environment and take them to robotics.

- In the second station, another university WiE student showed the children the Code Go Robot Mouse Activity Set. A set of educational toys that allow children to experience programming at an extremely initial level. Through the game, children program the path that a small mouse must follow to reach the end of an armed labyrinth placed at ground level, children place the sequence, two steps to the left, one straight, three to the right, and others.

- In the third station there was a new volunteer with a LEGO Mindstorms EV3 kit. All children had the opportunity to build a robot section under instruction 
and test it with a simple line follow program.

- In the penultimate station, management was carried out through the mechatronic engineering career, which has humanoid robots available at the institution. The amazement of children of basic levels of education when seeing and interacting with a robot of real proportions motivated them to enter the world of robotics.

- Finally, a project of linking with society was carried out by students of the Mechanical and Mechatronics Engineering degree, allowing children to relate the geography of Ecuador, mountain systems, and valleys with technology.

The groups rotated through each of the stations for an approximate time of 30 minutes, an ideal time to complete all the instructions and that each of the children can handle some of the equipment in the stations. The affinity group gifted a final individual souvenir to the visiting school. Previous days a collection of electronic elements such as resistors, capacitors, integrated circuits, and LEDs that the university members do not use anymore. Small humanoid and animal-shaped figures were built using creativity; the small armed character was placed on a $7 \mathrm{~cm}$ by $3 \mathrm{~cm}$ MDF wooden strip in which the Women in Engineering logo of the Universidad de las Fuerzas Armadas ESPE was printed.

In summary, with each of the mini workshops, topics were discussed and learning was focused on:

- Basic programming based on sequential instructions.

- Electronics and its implications with the real world through sensors.

- Robotics and programming, LEGO kits and humanoid Robot.

- Applications in the world using electronics.

A day full of experiences and memories was evaluated through oral questions to verify the visitors understanding at the end of the day. Before the workshop, many children were interviewed about their favorite profession as adults. They had thought about being doctors, teachers, firefighters, and among girls stylists and teachers were the most selected professions. At the end of the workshop, boys and girls expressed their enthusiasm for working with robots or being engineers.

3) RAS TT: The "RAS - Tour Technology" was an event organized by the Technical Chapter Robotics Automation Society of IEEE Ecuador Section in July 2019, a six-day tour of the main cities of Ecuador: Ibarra, Latacunga, Cuenca, Guayaquil, Manta and Quito, spreading the STEM methodology in Ecuador and conducting conferences and technical courses in each University of one of these cities. Two young students representing WiE ESPE actively contributed to this great project. On the agenda, there was a "Workshop of Educational Robotics," a course sponsored by IEEE Young Professionals and IEEE SIGHT Ecuador with the help of the EPICS in IEEE (Engineering Projects in Community Service) global fund. The two delegated students worked with children students from different cities fulfilling a robotics teaching agenda in zoomorphic robotic prototypes, built in the city of Loja. Being part of such a project provides experiences that can be replicated effectively in the Affinity Group.

4) Keynote Conferences with Distinguished Lecturer Karon McLean: In November of the previous year, IEEE RAS Ecuador requested a distinguished speaker through the IEEE DL program. WIE ESPE took the opportunity to hold an internal event at the University, WIE and RAS partnered by having a professional woman in charge of a higher-level conference with the theme "Making Haptics and its Design Accessible." The event was attended by students from several universities in the city; there were a total of 100 participants.

\section{KEY AsSOCIATIONS}

Inter-institutional cooperation is the meaning of promotion, progress towards new horizons with implications of greater importance. It is an agreement that allows two or more institutions to join forces around a shared vision. In the last year, we have sought to boost these cooperations, resulting in:

- Cooperation agreement with CR Ciencia y Robótica company.

- Participation of WiE ESPE in the inter-institutional agreement of the University and the Ministry of Education.

- Cooperation agreement between IEEE ESPE Student Branch and APM Electronics.

One of the advantages of CR Ciencia y Robótica, is its location near ESPE, in the Valle de los Chillos province of Pichincha. It is a company that provides educational, technological innovation services with a wide range of courses in robotics, digital and prototyping design, computer science, and creation of teaching content [8]. The General Manager of the company, former rector of the University of the Armed Forces, enthusiastically supports the IEEE, and the WIE ESPE team knows the capabilities of its members and trusts in the events that are assembled. The cooperation has been made in both directions, IEEE ESPE students have participated in several exhibitions of the company, and the company has collaborated with its facilities and equipment. The project, Day Girls in the ICTs described in the previous section, was supported by their teams, Neulog Sensors, and the Code Go Robot Mouse Activity Set. It is valuable to note that the group also conducts self-management to solve its activities and events, always keeping in mind the mission of IEEE worldwide, a nonprofit organization where WiE International is also supported.

WiE at the University effectively took advantage of its cooperation agreement with the Ministry of Education of Ecuador, being proactive and arriving with the proposal to give workshops to students in primary or secondary education that the ministry approves and issues the necessary permits to be able to do the job with minors.

Finally, the most significant benefit that IEEE ESPE, WiE, and its RAS Chapter has brought since 2018 has been the agreement with the store called APM Electronics, a trade of 
electronic elements and tools, project service, and 3D printing. The agreement was formalized on July 11, 2018, the main points that stand out are:

- University students who present their IEEE membership card receive a $15 \%$ discount on their purchases of materials..

- Teams made up of IEEE members participating in robotics competitions get a special discount of $35 \%$ discount for their prototypes.

The search for organizations with similar visions to the team continues and is one of the purposes of the year 2020. The contact with professionals invited to the conference cycles is used to form networking networks and achieve more goals.

\section{WIE GROWING GROUP}

The WIE affinity group of the Student Branch of the Armed Forces with the development of several student events focuses on involving more members and professionals in several projects that promote the integration of women and girls in science. Trying to always keep in mind and motivate women to participate in the events organized by IEEE Student Branch, spaces were created that rewarded academic achievements of engineering students, groups in which women played an important role. During the period in which the events were held, it is necessary to highlight the discussion and conferences "Women in Science" held in January 2019 during the IEEE Week ESPE and the celebration of Girls in ICTs. The event was a project in conjunction with the Ministry of Education, where the IEEE Student Branch experienced considerable growth in the number of members not only being part of the branch but taking action in the WIE affinity group. With this context, it is expected that by organizing this kind of event, more students and professionals of the university joint the team making it multidisciplinary.

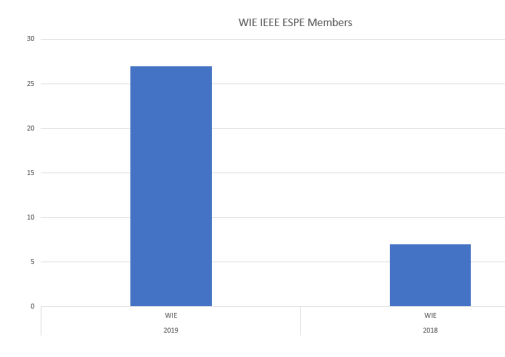

Fig. 3. WIE members at its activation 2018 and WIE members by the end of 2019

\section{Future Projects}

WIE ESPE is at the top of its performance, so it is necessary to continue the work and improve it. This section briefly describes two of the projects in the planning phase, most important of Women in Engineering ESPE in 2020, the execution of the IEEE Student-Teacher and Research Engineer
/ Scientist (STAR) Program in the city of Quito, Ecuador, which could be carried out with all the equipment, material and preparation that the group possesses, also through its strategic alliances. In general, the activities carried out in this program are recreational science workshops to primary or secondary education units, field visits to universities, or companies where young people can observe the work of engineers, challenges, or skills based on scientific applications and others. The following established idea is aimed at the manufacture of electronic Braille language learning tools for blind children, built and developed with the support of WiE International and the IEEE Special Interest Group on Humanitarian Technology (SIGHT) Affinity Group.

\section{CONCLUSIONS AND RECOMMENDATIONS}

The concrete structure of the WIE ESPE affinity group has been exposed and due to this, the work that can be done to contribute to the improvement the gender gap of the community and the country; to the empowerment of girls and young people in areas of science, technology, engineering and mathematics from our organization.

Is expected that this work serves as as a guide for future initiatives that include, as a recommendation, the creation of an evaluation rubric based on learning objectives and results, and which in turn allows quantifying and qualifying the impact it has in girls and young women, early learning of the technological world and its opportunities in an increasingly globalized society.

\section{ACKNOWLEDGMENT}

The project "IEEE Women in Engineering of Universidad de las Fuerzas Armadas ESPE" has been possible with the support of all affiliated and volunteer member students, their founders, for having the initiative and the courage to move the group forward through their constant support and interest in activities. The authors of this summary appreciate the support of University authorities, among the most important, those teachers who provide support outside their academic obligations, the IEEE ESPE Advisors.

\section{AUTHOR INFORMATION}

Victoria Yánez Garzón, IEEE - ESPE Student Branch Chair 2018. Automation and Control Electronics Engineering Undergraduate Student.

Universidad de las Fuerzas Armadas ESPE.

Andrea López López, IEEE WIE Student Branch Affinity Group Advisor

Universidad de las Fuerzas Armadas ESPE.

\section{REFERENCES}

[1] WiE, IEEE Women in Engineering Website, available: https://wie.ieee.org/

[2] UNESCO. (2017). Cracking the code: girls' and women's education in science, technology, engineering and mathematics (STEM), English ed. [ISBN: 978-92-3-100233-5] 
[3] Herdoiza 2015, Herdoíza, M. (2015). Construyendo Igualdad en la Educación Superior. Fundamentación y lineamientos para transversalizar los ejes de igualdad y ambiente. $1^{a}$ ed . - Quito: Senescyt/Unesco ISBN978-9978-339-10-7

[4] Ferreira Salazar C, García García K, Macías Leiva L, Pérez Avellaneda A, Tomsich C. MUJERES Y HOMBRES del Ecuador en Cifras III. Serie información estrategica, Spanish ed.[ISBN: 978-9942-07-390-7]

[5] WiE, IEEE Women in Engineering Website, available: https://wie ieee org/aboutieeewie

[6] WiE, IEEE Code of Ethics, available: https://www.ieee.org/about/corporate/governance/p7-8.html

[7] IEEE. (2017). IEEE guidelines for working with children, available: https://www.iee.org/about/volunteers/risk-insurance/ieee-activitieswith-children.html

[8] CR Ciencia \& Robótica, Ciencia \& Robótica Website, available: https://www.crcienciayrobotica.com/ 